\title{
Sub-Chronic Cadmium Exposure in Drinking Water Dysregulates Lipid and Glucose Metabolisms in Apoe (-/-) Mice: Molecular Insights Into the Etiology of Atherosclerosis
}

\section{Edozie Samuel OKPARA ( $\nabla$ samuelokpara16@gmail.com )}

Southern Medical University School of Public Health https://orcid.org/0000-0001-7255-2363

Wan Yu

Southern Medical University School of Public Health

Haibin Huang

Southern Medical University School of Public Health

\section{Song Jia}

Southern Medical University School of Public Health

\section{Wei Zhu}

Guangzhou Center for Disease Control and Prevention

\section{Guangyu YANG}

Guangzhou Center for Disease Control and Prevention

\section{Xingfen YANG}

Southern Medical University School of Public Health

Original investigation

Keywords: Cadmium, Atherosclerosis, Glucose dysfunction, ApoE (-/-) mice, Lipid dysfunction, Atherosclerotic plaques

Posted Date: June 16th, 2021

DOl: https://doi.org/10.21203/rs.3.rs-618912/v1

License: (9) This work is licensed under a Creative Commons Attribution 4.0 International License. Read Full License 
Sub-chronic cadmium exposure in drinking water dysregulates lipid and glucose metabolisms in $\mathrm{ApoE}^{(-/-)}$mice: Molecular insights into the etiology of atherosclerosis

Edozie S. Okpara ${ }^{\mathrm{a}, 1}$, Yu Wan ${ }^{\mathrm{a}, 1}$, Hai-bin Huang ${ }^{\mathrm{a}}$, Jia Song ${ }^{\mathrm{a}}$, Wei Zhu ${ }^{\mathrm{b}}$ Guangyu yang ${ }^{\mathrm{b}}$, Xing-fen Yang $\mathrm{a}^{\mathrm{a}^{*}}$

${ }^{a}$ Food Safety and Health Research Center, Guangdong Provincial Key Laboratory of Tropical Disease Research, School of Public Health, Southern Medical University, Guangzhou, China

${ }^{\mathbf{b}}$ Guangzhou Centre for Disease Control and Prevention

*Corresponding author: yangalice79@smu.edu.cn

${ }^{1}$ The authors contributed equally to this work

\begin{abstract}
Background: Exogenous exposure to cadmium is associated with cardiovascular diseases, including atherosclerosis, but experimental evidence elucidating the molecular events involved is still unclear, hence this study. We investigated whether sub-chronic cadmium exposure alone could cause a disruption in lipid and glucose metabolisms and whether the combined effect of these dysregulations could progressively lead to atherosclerosis in $\mathrm{ApoE}^{(--)}$mice.

Methods: Experiments were performed in male ApoE ${ }^{(--)}$mice (8 weeks $25 \pm 3 \mathrm{~g} ; \mathrm{n}=60$ ), which were randomly placed into four (4) groups according to body weight and administered cadmium $\left(\mathrm{CdCl}_{2}\right)$ 0, 50, 100 and $200 \mathrm{mg} / \mathrm{L}$, respectively in drinking water consecutively for 4 months. After treatment, changes in body weight were evaluated and mice plasma was analyzed for LDL, HDL, TCHO, TG, insulin and glucose levels. The collected samples were sent for histological examination in the $4^{\text {th }}$ month and two-way ANOVA was used for statistical analysis.

Results Levels of plasma LDL increased in all treatment groups but was statistically significant in the $4^{\text {th }}$ month across all treatment groups when compared both with the blank control group and the
\end{abstract}


first month mice. Plasma HDL levels were lowered in all treatment groups in the $2^{\text {nd }}$ and $4^{\text {th }}$ months when compared with the $1^{\text {st }}$ month mice. Statistically significant decreases in plasma HDL levels were also observed in the $2^{\text {nd }}$ month in the group receiving $\mathrm{CdCl}_{2}(100 \mathrm{mg} / \mathrm{L}$ and $200 \mathrm{mg} / \mathrm{L})$ when compared with the blank control. TCHO andTG levels increased but was statistically significant in the former in the $1^{\text {st }}, 2^{\text {nd }}$ and $4^{\text {th }}$ month at $\mathrm{CdCl}_{2}(100 \mathrm{mg} / \mathrm{L}$ and $200 \mathrm{mg} / \mathrm{L})$ and in the latter at the same dose only in the $4^{\text {th }}$ month. Moreover, fasting plasma glucose and insulin were elevated and lowered, respectively. Histological examination of aortal root also showed a dose-dependent increase in plaque formation, being most visible in the treatment group receiving $\mathrm{CdCl}_{2}(200 \mathrm{mg} / \mathrm{L})$.

Conclusion: In line with our hypothesis, sub-chronic oral exposure of $\mathrm{ApoE}^{(--)}$mice to cadmium dysregulated their glucose and lipid profiles and the combined effect of this may be a contributory molecular event in the development of atherosclerosis.

Keywords: Cadmium. Atherosclerosis. Glucose dysfunction. ApoE ${ }^{(--)}$mice. Lipid dysfunction. Atherosclerotic plaques 


\section{List of Abbreviations:}

$\mathbf{C d C l}_{2}$ : Cadmium chloride

Cd: Cadmium

$\mathbf{A p o E}^{(-/)}$: Apolipoprotein-E Knock-out mice (male)

ApoE protein: Apolipoprotein-E

TG: Triglycerides

LDL: Low-density Lipoproteins

HDL: High-density Lipoproteins

Ox-LDL: Oxidized LDL

Sd-LDL: Small dense LDL

LDLR: LDL receptor

TCHO: Total cholesterol

VLDLs: Very Low-density Lipoproteins

IDLs: Intermediate Density Lipoproteins

ASCVD: Atherosclerotic Cardiovascular Diseases

GZCDC: Guangzhou Centre for Disease Control and Prevention

NO: Nitric Oxide

PCA: Protocatechuic Acid

Fe: Iron 


\section{BACKGROUND AND GAPS}

Cadmium (Cd) is apparently ubiquitous (since it is found in plants - vegetables, fruits and grains, and shellfish and organic meats ${ }^{\text {(1], }}$ cytotoxic, non-essential environmental element and heavy metal which is almost equitably known for its role in the pneumonia and gastrointestinalbased deaths due to the itai itai disease of the 1960s as well its role as a possible causal agent in the development and progression of atherosclerosis ${ }^{[1] .}$ However, laboratory evidence for the latter is at best rudimentary. Fransson M.N. et. al., $2014^{[2]}$ pointed out the exceptionally long half-life of cadmium (up to 45 years and over), even though only $1-5 \%$ of ingested and $20-25 \%$ of inhaled Cd is absorbed, respectively. Park J.D. et al., $2002^{[3]}$ reported an inverse relationship between intestinal absorption of $\mathrm{Cd}$ and the levelof iron-stores in tissues - the lower the iron-store, the higher the level of intestinal absorption of $\mathrm{Cd}$ and vice versa. This negative relationship notwithstanding Park and colleagues also reported that available data from laboratory experimental and clinical studies are still unclear as to the impact of apolipoprotein-E (ApoE) protein or ApoE protein deficiency in determining the level of iron in animal tissues and ipso facto, $\mathrm{Cd}$ intestinal uptake. This relationship between $\mathrm{Cd}$ and Fe intake is critical because several studies have shown that the efficiency of Cd intake by the duodenal enterocytes is via the Feregulated, proton-coupled transporter, DMT1 and this, in turn is greatly influenced by iron tissue content $^{[4,5]}$. Additionally, several studies carried out by a number of other investigators have since corroborated these findings by Park and colleagues ${ }^{[6-11] .}$ Furthermore, while mechanistic studies are replete on the possible role of chronic Cd exposure in the pathophysiology of atherosclerosis and on the possible role of $\mathrm{Cd}$ in the epidemiology of atherosclerosis ${ }^{[7-9],}$ laboratory experimental data supporting an association between $\mathrm{Cd}$ exposure and atherosclerosis is rather unclear and controversial, hence the reason for the design of this study.

The two dominant routes of $\mathrm{Cd}$ routes for $\mathrm{Cd}$ absorption for humans are smoke inhalation (active smoking of tobacco or second-hand smoking) and diet (water and vegetables 
contaminated from water or from industrial settings). A critical omissionin these exposure routes is $\mathrm{Cd}$ pollution directly from drinking water sources, which humans, especially rural dwellers are highly prone to. It is crucial to state that water is considered diet by most people as it constitutes an important fraction of our daily food intake. However, direct intake of heavymetal polluted water, especially by $\mathrm{Cd}$ is not the commonest route of exposure. He et. al. (2015) stated that over $70 \%$ of all $\mathrm{Cd}$ that get into the body of humans come from the consumption of leafy vegetables. Moreover, Huang et al. (2020) ${ }^{[12]}$ reported that each leafy vegetable type has a discrete accumulation (measured by its bioconcentration factor, BCF) and transport (measured by its translocation factor, TF) capacities [12]. Furthermore, in a cross-sectional study for the dietary assessment of Cd exposure amongst 753 South China rural dwellers, P. Zhu et. al. (2016) ${ }^{[13]}$ concluded that in the polluted areas studied, rice was the most important food category, contributing $77.49 \%$ of the total exposure, appreciably exceeding exposure reported by He et. al. above.

Mechanistic studies have established a causal role for lipids (principally low-density lipoproteins-cholesterol, LDL-C) and hypercholesterolemia in the atherogenesis of atherosclerotic cardiovascular disease (ASCVD). Peng et. al. $\left.{ }^{[14}\right]$ defined LDL-C as an independent risk factor for atherosclerosis. Furthermore, dyslipidemia (aberrant regulation of lipid metabolism) and hyperlipidemia (high level of blood plasma lipids) have also been described by Avani and colleagues, as prerequisite risk factors for the development and progression of clinically detectable atherosclerosis ${ }^{[15]}$ Additionally, Hayashi et. Al [16] summarized from laboratory experimental research findings that high glucose concentrations suppress the levels of caveolin-1 expression, reducing the number of caveolae (vesicular invaginations of the plasma membrane that mediate the intracellular transport of lipids such as cholesterol), and ipso facto, increasing the risk of development and progression of atherosclerosis. The significance and novelty of the proposed study lies in the fact that, for the first time, an 
attempt is being made towards providing laboratory experimental evidence of the possible combinatory effect of glucose and lipid dysregulation in the development of atherosclerosis, especially in $\mathrm{ApoE}^{(-/)}$mice.

In addition to the dearth in laboratory experimental data on the combinatory effect of disruption of glucose and lipid metabolism in the development and progression of atherosclerosis, another thinking that is a strong factor in the design of this study, is the public health concern of chronic cadmium (and other heavy metal) exposure amongst at-risk, rural populations who are suffering huge socio-economic disparities and are constantly exposed to heavy-metal pollution of their drinking and cooking water sources by manufacturing industries. We are hopeful that findings from this study could serve as an effective prevention strategy, especially if supported by government-directed policies that will regulate the deposition of harmful substances into water-bodies of communities. Thus, the novelty, significance and broader translational potential of the proposed study is considered high, particularly in the area of providing a practical, lifestylebased intervention towards stemming the incidence of atherosclerotic cardiovascular disease which according to the WHO, is the leading cause of death, contributing $29.52 \%$ of annual global deaths over the last decade ${ }^{[17]}$. 
Our overall research hypothesis in the design of this study is that when exposed to sub-chronic Cd treatment in drinking water, ApoE ${ }^{(-/-)}$mice will show a disruption in glucose and lipid metabolism which may progressively lead to the development of atherosclerosis. We also set-out the following as the key research objectives for this investigation:

I. To provide laboratory experimental evidence for the first time, of the possible combinatory effect of the disruption in glucose and lipid metabolism in the pathology of atherosclerosis.

II. To demonstrate the established reliability of $\mathrm{ApoE}^{(--)}$mice as a natural experimental model for the development of atherosclerosis.

III. To broaden the frontiers of health promotion and education on the role of diet in the etiology of a number of non-communicable diseases and encourage positive lifestyle behaviors especially in at-risk populations and in turn, cause an overall improvement in public health. 


\section{METHODS}

\section{1: Chemicals:}

Cadmium chloride $\left(\mathrm{CdCl}_{2}\right)$ was purchased from Sigma-Aldrich (St Loius, MO). Mouse ELISA kits were purchased from Crystal Chem and used for the quantification of fasting plasma insulin. Commercial kits for the determination of blood total cholesterol (TCHO), triglycerides (TG), highdensity lipoproteins (HDL), low-density lipoproteins (LDL), glucose were purchased from Nanjing Jiancheng Bioengineering Institute Co., Ltd, (Nanjing Jiangsu, China).

\section{2: Experimental design:}

The mice $(n=60)$ were randomly assigned to four groups of 15 animals each, and would be treated by exposure to $\mathrm{Cd}$ in drinking water for $\mathbf{4}$ consecutive months as follows:

Group 1 (control): Blank control taking standard chow + Cd-free drinking water

Group 2 (treatment 1): Standard mice chow $+\mathrm{Cd}$ at 50mg/L

Group 3 (treatment 2): Standard mice chow + Cd at 100mg/L

Group 4 (treatment 3): Standard mice chow + Cd at 200mg/L

In line with the experiment design, particularly the central hypothesis of this study, the lipid and glucose levels in the treatment groups were quantified on a monthly basis to check whether lipid and glucose metabolism were normal or dysfunctional.

\section{3: Study animals}

Male ApoE ${ }^{(-/)}$mice ( 8 weeks $25 \pm 3 \mathrm{~g} ; \mathrm{n}=60$ ), were bought from the Guangdong medical laboratory animal centre, would be used for this investigation. The mice would will housed in plastic cages and placed in well-ventilated vivarium, provided standard mice chow and water ad libitum, and subjected to natural photoperiod of $12 \mathrm{~h}$ night/day before the commencement of the experiment. This period of acclimatization was 7 days. The experimental protocol was executed after approval and in agreement with the rules and guidelines of the Guangzhou Centre for 
Disease Control and Prevention (GZCDC). All the mice received humane care in accordance with the conditions stated in with Chinese government requirements concerning animal care.

\section{4: Sample Collection}

Quantitative experimental data collected from benchtop assays was used for this investigation. Following the expiration of the exposure period (16 weeks), all experimental animals were killed using chloral hydrate $(4 \% 10 \mathrm{ml} / \mathrm{kg})$ anesthesia after the final body weight of the mice were measured. Blood samples were collected from retro-orbital venous plexus using plain glass tubes (in the $1^{\text {st }}$ and $2^{\text {nd }}$ month of exposure). In the $4^{\text {th }}$ month, source of blood collection was switched to the abdominal aorta. Animals were then killed by cervical dislocation, following 12 hours fasting after the last treatment. Plasma samples were prepared by centrifuging the clotted blood at $1000 \mathrm{~g}$ for $15 \mathrm{~min}$. The plasma samples were thereafter stored frozen at $80^{\circ} \mathrm{C}$ until the lipid and insulin quantifications/analyses were performed using commercially available kits. The aorta was quickly and carefully removed, weighed and processed for histological examination.

\section{5: Experimental protocol}

All protocol were followed according to the guide provided by the manufacturer in the commercially available kits purchased for this investigation.

\section{6: Histopathological examination}

The carotid arteries were collected from the sacrificed mice at 14 weeks. Vessel were fixed in 4\% paraformaldehyde dehydrated to staining and analysis of atherosclerotic plaques. For each animal, the aortic cross sections were mounted on gelatine-coated slides and stained with Oil Red O (Sigma-Aldrich, St. Louis, MO, USA) to detect the neutral lipids. Representative images of all 
groups were captured with an optical microscope (Zeiss Axioscope A1, Heidelberg, Germany) using a $\times 4$ objective.

\section{8: Statistical analysis:}

All results were expressed as mean \pm Standard Deviation $( \pm$ SD). Statistical analysis was done using two-way analysis of variance (ANOVA) with the aid of SPSS (IBM SPSS, Statistics; Version 26). Values of $P<0.05$ were considered significant when compared with the blank control or the $1^{\text {st }}$ month. Kolmogorov-Smirnov test for normality was performed and showed that all data were normally distributed. 


\section{RESULTS}

\section{1: Effects of Cd exposure (drinking water) on body weight (g) of ApoE ${ }^{(--)}$mice for 4 months}

A number of studies have reported significant decreases in mice body weight following exposure to a toxicant in combination to high-fat diet (HFD) or when there is co-exposure involving two toxicants ${ }^{[36,37]}$ Zhang and colleagues reported a significant decrease in bodyweight in mice treated with HFD plus Cd when compared with the HFD alone group and the group receiving low doses of Cd alone, intraperitoneally administered twice a week ${ }^{[36] .}$ Even though our study involved a more frequent administration of $\mathrm{Cd}$, no significant changes in body weight were observed in the 16 weeks of exposure, suggesting that body weight may in fact only be significantly altered when exposure of mice to a toxicant is augmented with a secondary intervention such as high-fat diet. We represented observed body weight trends in Fig 3.1 below

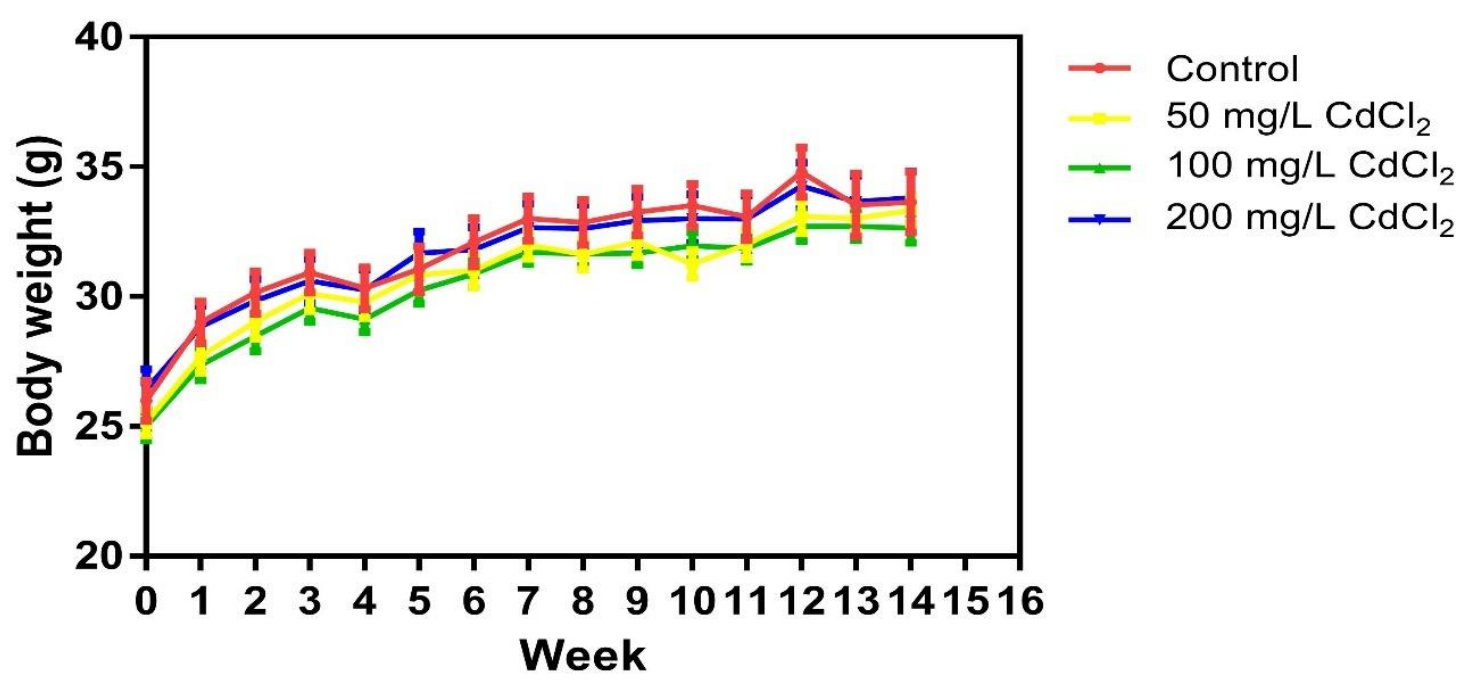

Fig. 3.1 Body weight curve of $\mathrm{ApoE} \mathrm{E}^{(--)}$mice sub-chronically exposed to $\mathrm{CdCl}_{2}$ (drinking water) for 16 consecutive weeks (4 months) 
3.2: Effects of sub-chronic Cd exposure (drinking water) on plasma HDL levels of ApoE ${ }^{(--)}$mice for 4 months

With respect to plasma HDL concentration, our results showed that plasma levels where generally lowered in the treatment groups when compared with the blank control group, albeit, in a dose-dependent manner. This reduction in plasma HDL levels was only statistically significant in the $2^{\text {nd }}$ and $4^{\text {th }}$ month in the treatment group when compared with the $1^{\text {st }}$ month mice. Statistically significant decreases in plasma HDL levels were also observed in the $2^{\text {nd }}$ month in the group receiving $\mathrm{CdCl}_{2}(100 \mathrm{mg} / \mathrm{L}$ and $200 \mathrm{mg} / \mathrm{L})$ when compared with the blank control. A summary of this result trend is presented in Table 3.1 and Fig 3.2D below.

\section{3: Effects of sub-chronic Cd exposure (drinking water) on plasma LDL levels of ApoE ${ }^{(--)}$mice} for 4 months

Table 3.1 and Fig 3.2C below shows observed trends in plasma LDL levels in the exposure groups over a period of 4 months. While plasma LDL levels generally increased in a dosedependent manner in the $1^{\text {st }}$ and $2^{\text {nd }}$ months of exposure when compared with the blank control group, statistically significant increases were only seen in the $4^{\text {th }}$ month across all treatment groups at the two levels of comparison made. A closer look at the plasma LDL data in the $4^{\text {th }}$ month as presented, shows that in all treatment groups, plasma LDL levels significantly increased when each of the dose groups were compared with the blank control group and also when comparisons were done in plasma LDL levels with the $1^{\text {st }}$ month mice, stressing perhaps the role

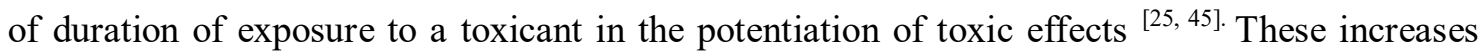
followed a dose-dependent manner. 


\section{4: Effects of sub-chronic Cd exposure (drinking water) on plasma TCHO levels of ApoE ${ }^{(-/)}$ mice for 4 months}

In the $1^{\text {st }}$ month of the exposure, our results showed that when compared with the blank control group, plasma TCHO levels increased in the treatment groups receiving $\mathrm{CdCl}_{2}(100 \mathrm{mg} / \mathrm{L}$ and $200 \mathrm{mg} / \mathrm{L})$. While TCHO levels increased in the group receiving $\mathrm{CdCl}_{2}(50 \mathrm{mg} / \mathrm{L})$, it was only statistically significant in the group receiving $\mathrm{CdCl}_{2}(100 \mathrm{mg} / \mathrm{L})$ when compared with the blank control group in the $4^{\text {th }}$ month. Further comparisons of the group receiving $\mathrm{CdCl}_{2}(200 \mathrm{mg} / \mathrm{L})$, with the blank control group as well as with the $1^{\text {st }}$ month mice, showed statistically significant increases. We also observed a statistically significant increase in plasma TCHO levels in the $2^{\text {nd }}$ month in mice receiving $\mathrm{CdCl}_{2} 100 \mathrm{mg} / \mathrm{L}$ when compared with the $1^{\text {st }}$ month mice, stressing again the role of duration in exacerbating dysregulation in lipid homeostasis. These results, elucidated in Table 3.1 and Fig 3.2B below, were observed to follow a dose-dependent manner.

\section{5: Effects of sub-chronic Cd exposure (drinking water) on plasma TG levels of ApoE ${ }^{(-/))}$mice for 4months}

Plasma TG levels increased dose-dependently in all treatment groups when compared with the blank control in the $1^{\text {st }}$ and $2^{\text {nd }}$ months of exposure. Statistically significant increases were first seen in the $4^{\text {th }}$ month in the group receiving $\mathrm{CdCl}_{2} 100 \mathrm{mg} / \mathrm{L}$ when compared with the $1^{\text {st }}$ month mice and also statistically significant in the group receiving $\mathrm{CdCl}_{2} 200 \mathrm{mg} / \mathrm{L}$ when compared with both the blank control and the $1^{\text {st }}$ month mice. Further comparison of plasma TG levels in the dose group receiving $\mathrm{CdCl}_{2}(200 \mathrm{mg} / \mathrm{L})$ and the first month mice, showed a statistically significant increase, again stressing the role of duration of exposure in exacerbating toxicities due to a toxicant. Table 3.1 and Fig 3.2 A, give a summary of this result trend. 
Table 3.1 Impact of sub-chronic $\mathrm{CdCl}_{2}$ exposure (drinking water) on lipid profiles of ApoE ${ }^{(--)}$mice

\begin{tabular}{|c|c|c|c|c|}
\hline & Control & $50 \mathrm{mg} / \mathrm{L} \mathrm{CdCl}{ }_{2}$ & $100 \mathrm{mg} / \mathrm{L} \mathrm{CdCl}{ }_{2}$ & $200 \mathrm{mg} / \mathrm{L} \mathrm{CdCl}{ }_{2}$ \\
\hline \multicolumn{5}{|c|}{ TG (mmol/L) } \\
\hline $1^{\text {st }}$ month & $1.19 \pm 0.30$ & $1.23 \pm 0.16$ & $1.24 \pm 0.28$ & $1.50 \pm 0.30$ \\
\hline $2^{\text {nd }}$ month & $1.28 \pm 0.06$ & $1.30 \pm 0.04$ & $1.32 \pm 0.29$ & $1.65 \pm 0.11$ \\
\hline $4^{\text {th }}$ month & $1.76 \pm 0.04$ & $1.83 \pm 0.37$ & $2.00 \pm 0.55^{\mathrm{b}}$ & $3.04 \pm 1.00^{\mathrm{ab}}$ \\
\hline \multicolumn{5}{|c|}{ TCHO (mmol/L } \\
\hline $1^{\text {st }}$ month & $2.68 \pm 2.07$ & $4.95 \pm 1.10$ & $5.42 \pm 0.94^{\mathrm{a}}$ & $5.51 \pm 0.68^{\mathrm{a}}$ \\
\hline $2^{\text {nd }}$ month & $5.58 \pm 0.70^{b}$ & $6.79 \pm 1.88$ & $8.14 \pm 0.57^{b}$ & $8.67 \pm 0.64^{a b}$ \\
\hline $4^{\text {th }}$ month & $6.33 \pm 1.29^{b}$ & $7.32 \pm 1.13$ & $10.17 \pm 1.78^{a b}$ & $14.03 \pm 2.01^{\mathrm{ab}}$ \\
\hline \multicolumn{5}{|c|}{$\mathrm{LDL}(\mathrm{mmol} / \mathrm{L})$} \\
\hline $1^{\text {st }}$ month & $3.00 \pm 0.87$ & $3.39 \pm 0.59$ & $3.62 \pm 0.78$ & $4.17 \pm 0.19$ \\
\hline $2^{\text {nd }}$ month & $3.18 \pm 0.48$ & $3.92 \pm 0.12$ & $4.24 \pm 0.50$ & $4.62 \pm 1.05$ \\
\hline $4^{\text {th }}$ month & $4.45 \pm 0.92$ & $11.39 \pm 2.00^{a b}$ & $11.99 \pm 1.55^{a b}$ & $12.82 \pm 1.17^{a b}$ \\
\hline \multicolumn{5}{|c|}{ HDL (mmol/L) } \\
\hline $1^{\text {st }}$ month & $3.67 \pm 0.26$ & $3.58 \pm 0.31$ & $3.35 \pm 0.54$ & $3.13 \pm 0.15$ \\
\hline $2^{\text {nd }}$ month & $3.21 \pm 0.31$ & $2.61 \pm 0.57^{b}$ & $2.43 \pm 0.43^{a b}$ & $2.11 \pm 0.19^{a b}$ \\
\hline $4^{\text {th }}$ month & $1.63 \pm 0.24$ & $1.58 \pm 0.09^{b}$ & $1.30 \pm 0.12^{\mathrm{b}}$ & $1.13 \pm 0.08^{b}$ \\
\hline
\end{tabular}

${ }^{\mathrm{a}} P<0.05$ vs Control; ${ }^{\mathrm{b}} P<0.05$ vs $1^{\text {st }}$ month 

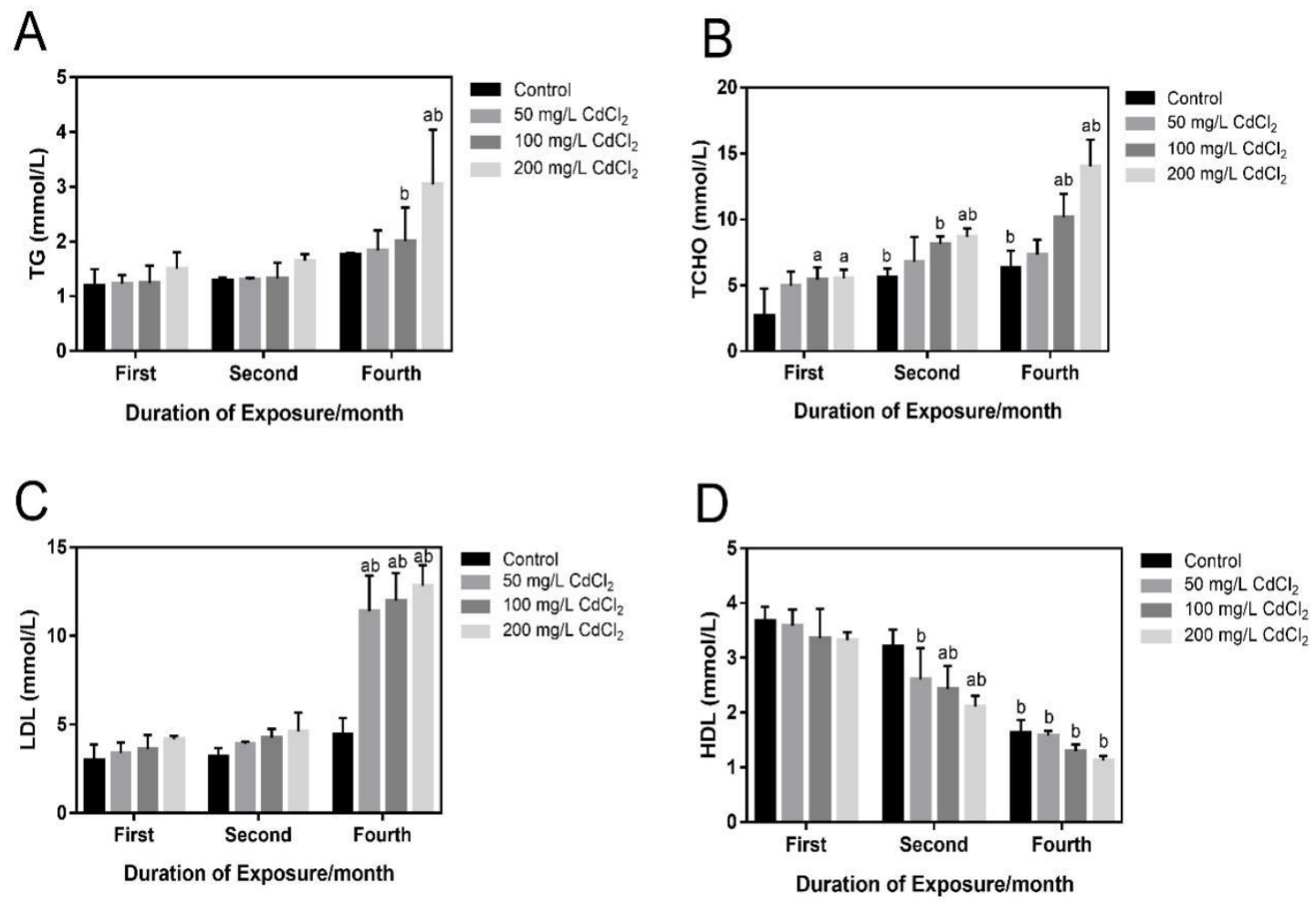

Figure 3.2 Impact of sub-chronic $\mathrm{CdCl}_{2}$ exposure (drinking water) on lipid profiles of $\mathrm{ApoE} \mathrm{E}^{(--)}$ mice

\author{
(A) TG; (B) TCHO; (C) LDL; (D)HDL \\ ${ }^{\mathrm{a}} P<0.05$ vs Control; ${ }^{\mathrm{b}} P<0.05$ vs $1^{\text {st }}$ month
}

\title{
3.6: Effects of sub-chronic Cd exposure (drinking water) on plasma insulin levels of ApoE (-/-) mice for 4 months
}

We found, as presented in Table 3.2 and Fig 3.3B below, that while fasting plasma insulin level decreased in all the exposure groups when compared with the blank control, this decrease was only significant in the $2^{\text {nd }}$ and $4^{\text {th }}$ month. Further comparisons of fasting plasma insulin levels in the $2^{\text {nd }}$ and $4^{\text {th }}$ months with the $1^{\text {st }}$ month mice, also showed a statistically significant decrease. These decreases, across the two levels of comparisons, were seen to follow a dose-dependent trend. 


\section{7: Effects of sub-chronic Cd exposure (drinking water) on fasting plasma glucose levels of ApoE $\left.{ }^{(-/)}\right)$mice for 4 months}

Fasting plasma glucose level in the treatment group when compared with the blank control group, was seen to increase steadily during the entire duration of exposure in a dose-dependent manner and was only statistically significant in the treatment group receiving $\mathrm{CdCl}_{2}(200 \mathrm{mg} / \mathrm{L})$ in the $1^{\text {st }}$ month. A similar trend was also observed in the $2^{\text {nd }}$ month. In the $4^{\text {th }}$ month, however, comparisons between fasting blood glucose levels between the blank control groups of the $1^{\text {st }}$ and $4^{\text {th }}$ month mice, showed a curious statistically significant increases in fasting plasma glucose levels underscoring the point that $\mathrm{ApoE}{ }^{(--)}$mice, even in the absence of an inducing toxicant (such as $\mathrm{Cd}$ ), are able to experience elevated/dysregulated fasting blood glucose levels, which may result in hyperglycemia if the conditions are maintained for an extended period of time.

Mice groups receiving $\mathrm{CdCl}_{2}(50 \mathrm{mg} / \mathrm{L}$ and $100 \mathrm{mg} / \mathrm{L})$ also showed statistically significant increases in fasting plasma glucose levels when compared with the $1^{\text {st }}$ month exposure mice. Table 3.2 and Fig 3.3 A below give a summary of observed trends.

Table 3.2 Impact of sub-chronic $\mathrm{CdCl}_{2}$ exposure (drinking water) on glucose and insulin level of $\mathrm{ApoE}^{(--)}$mice

\begin{tabular}{lllll}
\hline & Control & $50 \mathrm{mg} / \mathrm{L} \mathrm{CdCl}_{2}$ & $100 \mathrm{mg} / \mathrm{L} \mathrm{CdCl}_{2}$ & $200 \mathrm{mg} / \mathrm{L} \mathrm{CdCl}_{2}$ \\
\hline GLU (mg/L) & & & & \\
$1^{\text {st }}$ month & $4.80 \pm 0.89$ & $5.50 \pm 1.11$ & $6.17 \pm 0.35$ & $8.70 \pm 1.74^{\mathrm{a}}$ \\
$2^{\text {nd }}$ month & $6.17 \pm 2.45$ & $7.50 \pm 1.72$ & $8.07 \pm 2.04$ & $9.47 \pm 0.82^{\mathrm{a}}$ \\
$4^{\text {th }}$ month & $8.32 \pm 0.66^{\mathrm{b}}$ & $8.69 \pm 1.02^{\mathrm{b}}$ & $9.33 \pm 2.00^{\mathrm{b}}$ & $10.06 \pm 1.08$ \\
\hline INS (pg/mL) & & & & \\
$1^{\text {st }}$ month & $290.60 \pm 105.47$ & $284.30 \pm 35.33$ & $277.50 \pm 38.25$ & $236.30 \pm 33.45$ \\
$2^{\text {nd }}$ month & $260.20 \pm 54.75$ & $152.40 \pm 14.211^{\mathrm{ab}}$ & $146.00 \pm 12.02^{\mathrm{ab}}$ & $139.20 \pm 27.90^{\mathrm{ab}}$
\end{tabular}


$4^{\text {th }}$ month $\quad 236.00 \pm 38.28 \quad 126.40 \pm 9.21^{\text {ab }} \quad 113.00 \pm 16.61^{\text {ab }} \quad 106.20 \pm 22.56^{\text {ab }}$

${ }^{\mathrm{a}} P<0.05$ vs Control; ${ }^{\mathrm{b}} P<0.05$ vs $1^{\text {st }}$ month
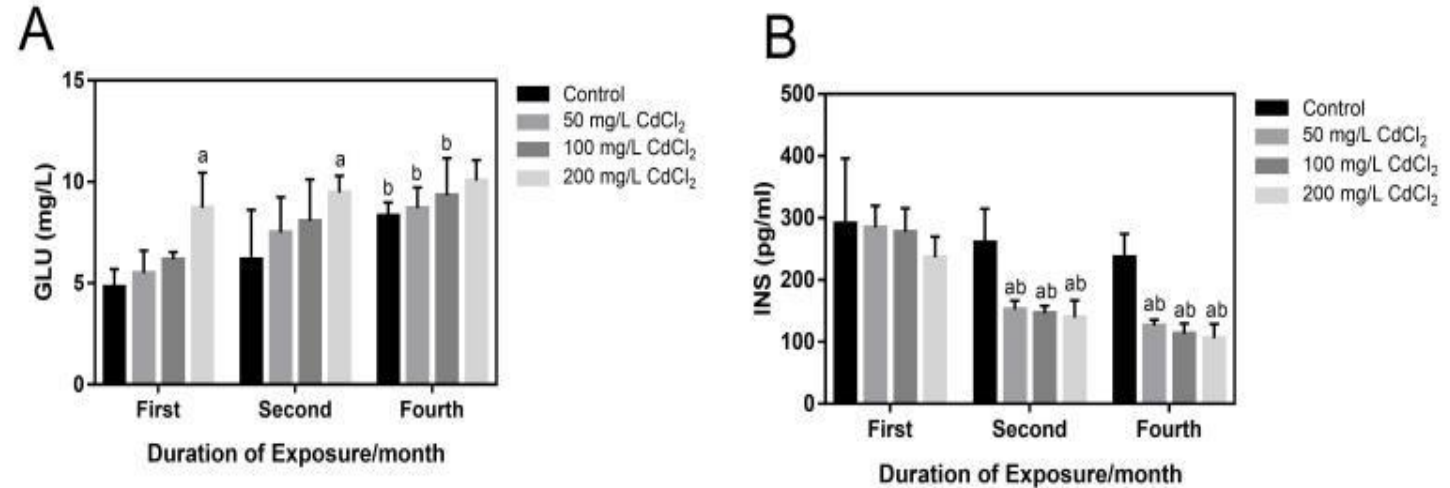

Figure 3.3 Impact of sub-chronic $\mathrm{CdCl}_{2}$ exposure (drinking water) on blood glucose and plasma insulin of $\mathrm{ApoE}^{(--)}$mice

(A) Fasting blood glucose (GLU); (B) Plasma insulin (INS)

${ }^{\mathrm{a}} P<0.05$ vs Control; ${ }^{\mathrm{b}} P<0.05$ vs $1{ }^{\text {st }}$ month

\section{8: Effects of sub-chronic Cd exposure (drinking water) on mice histology in the $4^{\text {th }}$ month}

Histological examinations from our study showed that in the $4^{\text {th }}$ month, atherosclerotic plaques/lesions (colored: red) developed across all the treatment groups when compared with the blank control group.

The Fig 3.4 below shows that at $\mathrm{CdCl}_{2}(50 \mathrm{mg} / \mathrm{L})$, the plaques were seen to nascent and visibly diffused around the periphery of aortal root when compared with the blank control. More visible lesions are however seen at $\mathrm{CdCl}_{2}(100 \mathrm{mg} / \mathrm{L}$ and $200 \mathrm{mg} / \mathrm{L})$, suggesting a dose-dependent progression in plaque visibility. 


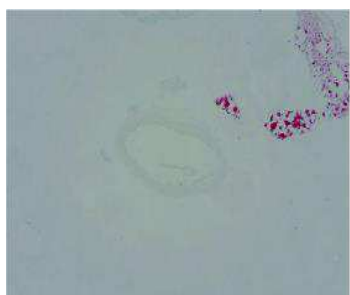

Control

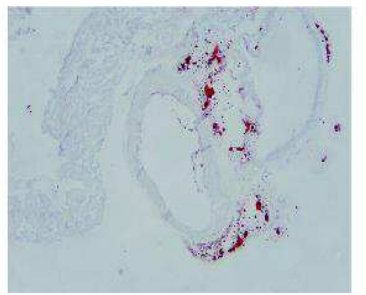

$50 \mathrm{mg} / \mathrm{L} \mathrm{CdCl}_{2}$

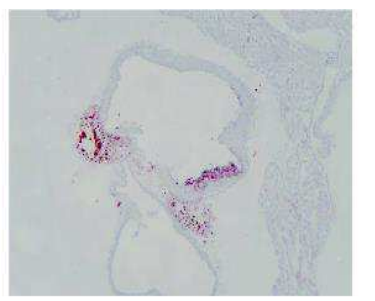

$100 \mathrm{mg} / \mathrm{L} \mathrm{CdCl}_{2}$

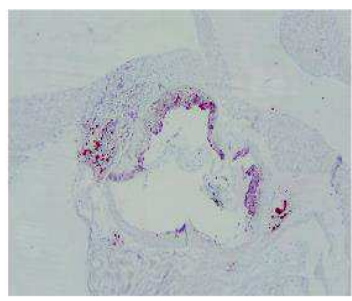

$200 \mathrm{mg} / \mathrm{L} \mathrm{CdCl}_{2}$

Figure 3.4 Histological examination of aortal root in $\mathrm{CdCl}_{2}$-exposed $\mathrm{ApoE}^{(--)}$mice at the $4^{\text {th }}$ month (Oil red O, 40x) 


\section{DISCUSSION}

Atherosclerosis is a chronic inflammatory driven by the inter-play between pro and antiinflammatory factors in the aorta ultimately leading to the formation of lipid rich plaques or foam cells in the intima areas of coronary arteries ${ }^{[18]}$. Centrally implicated in this chronic pathological state are endothelial dysfunction and inflammation, which in turn, allows monocytes to differentiate into macrophages, allowing the latter to penetrate into the compromised walls of the endothelium resulting in the formation of foam cell atherosclerotic plaques in the intima areas of the endothelial cells of the coronary arteries ${ }^{[19]}$. Rupture of these foam cell-laden atherosclerotic plaques or lesions manifests clinically as ischemic stroke, ischemic heart disease and peripheral artery disease ${ }^{[20,21,22] .}$ The cascade of molecular events driving this inflammatory disease, including nitric oxide (NO), MicroRNAs, interleukin-6, oxidized LDL (ox-LDL) and a host of other downstream effectors have been extensively discussed and established by several studies ${ }^{[23-28]}$

In the present study, 60 mice ( 8 weeks $25 \pm 3 \mathrm{~g}$ ), fed with standard mice chow, were placed into four groups and chronically exposed to $\mathrm{CdCl}_{2}$ in their drinking water for 4 months. Body weight changes through the course of exposure were evaluated and presented as a body weight curve because no statistically significant changes were observed. 12-hour fasting blood samples were collected for serum insulin and plasma glucose determination, shortly after the last treatment dose was administered and the animals and the animals final body weight taken.

Blood collection was via the retro-orbital artery using a glass cannula and then directly placed into an EDTAK2 vacuum blood collection tube. Glucose was tested using blood collected from the retro-orbital artery and the abdominal aorta. It is however important to mention that we switched blood collection source from the retro-orbital venous plexus after the $1^{\text {st }}$ and $2^{\text {nd }}$ month to the abdominal aorta in the $4^{\text {th }}$ month due to reasons of mice mortality and the need to increase blood collection volume per unit collection. 
Body weight changes in mice during the course of exposure was presented as a body weight curve. We found no significant differences in weight changes during the course of the exposure and this was consistent with the work of Rafa S. Ameer ad colleagues ${ }^{[29] . ~ I n ~ o u r ~ s t u d y, ~ w e ~ f o u n d ~}$ that there was a steady and dose-dependent increase in plasma blood glucose levels in the treatment groups when compared with the blank control group, and that while this increase was observed from the $1^{\text {st }}$ to the $4^{\text {th }}$ month, statistically significant increases in the treatment groups when compared with $1^{\text {st }}$ month exposure animals, were only observed in the $4^{\text {th }}$ months in treatment groups receiving $\mathrm{CdCl}_{2}(50 \mathrm{mg} / \mathrm{L})$ and $\mathrm{CdC}_{12}(100 \mathrm{mg} / \mathrm{L})$. Additionally, we found a rather curious statistically significant increase in the fasting plasma glucose level of the $4^{\text {th }}$ month blank control when compared with the $1^{\text {st }}$ month blank control mice, suggesting that these dysregulations can still take place in these mice types even in the absence of an environmental toxicant such as $\mathrm{Cd}$. The biological plausibility of potentiated hyperglycemia was not only supported by the work of Hayashi and colleagues cited above, but it also highlights how oxidative stress (in this case from NADPH oxidase) can work synergistically high plasma glucose level to downregulatethe number and size of caveolae in the plasma membrane of macrophages and ipso facto, impede the efficient intracellular translocation of lipids, especially cholesterol ${ }^{[16]}$.

HDL plays a crucial role in resolving atherosclerosis by mitigating oxidative and inflammatory processes involved in the initiation and potentiation of the process and has also been found to be an effective driver of reverse cholesterol transport (transport of cholesterol away from the peripheral tissues) ${ }^{[30,31,32]}$. With respect to plasma HDL concentration, our results show that plasma levels where generally lowered in the treatment groups when compared with the blank control group, albeit, in a dose-dependent manner. Further comparisons with the control as well as comparisons with the plasma HDL levels in the $1^{\text {st }}$ month, showed statistically significant decreases plasma $\mathrm{HDL}$ levels in all treatment groups. While mice receiving $\mathrm{CdCl}_{2}$ $(50 \mathrm{mg} / \mathrm{L})$ showed a statistically significant decrease in plasma HDL in the $2^{\text {nd }}$ month when 
compared with the $1^{\text {st }}$ month, additional statistically significant reductions in plasma HDL were seen in exposure groups receiving $\mathrm{CdCl}_{2}(100 \mathrm{mg} / \mathrm{L})$ and $\mathrm{CdCl}_{2}(200 \mathrm{mg} / \mathrm{L})$, when compared with the $1^{\text {st }}$ month. In the $4^{\text {th }}$ month, plasma HDL levels were seen to significantly decrease in all treatment groups when compared with the $1^{\text {st }}$ month mice Comparisons of plasma HDL levels in the treatment groups with the control exposure did not show any statistically significant decrease. Klaus G. Parhofer in his 2015 seminal publication ${ }^{[32]}$ to explain curious biological plausibility with regards to plasma HDL levels following exposure to an environmental toxicant, posits that the relationship between atherosclerosis and HDL is more complex than the relationship between LDL and atherosclerosis and that the functionality of the HDL system is more important in reducing plasma cholesterol levels (and in turn, atherosclerosis) than increase in HDL concentration [32]. However, in our study, we did not observe any trends in plasma HDL levels inconsistent or complicated to warrant a justification of Parhofer's findings. The treatment mice all showed decreased HDL levels when compared both with the control group and when the $4^{\text {th }}$ month mice were compared with the $1^{\text {st }}$ month treatment mice.

While plasma LDL levels generally increased in a dose-dependent manner in the $1^{\text {st }}$ and $2^{\text {nd }}$ months of exposure when compared with the blank control group, statistically significant increases were only seen in the $4^{\text {th }}$ month across all treatment groups at the two levels of comparison made. A closer look at the plasma LDL data as presented, shows that in all treatment groups, plasma LDL levels significantly increased when each of the dose groups were compared with the blank control group and also when comparisons are done in plasma LDL levels between the $1^{\text {st }}$ month and other months, stressing perhaps the role of duration of exposure to a toxicant in the potentiation of toxic effects ${ }^{[25,45] .}$ While this trend followed a dose-dependent fashion, this was consistent with previous research work done in this area by Lu and Daugherty, 2015 [33].

A statistically significant increase in plasma TCHO level was observed in the exposure group receiving $\mathrm{CdCl}_{2}(200 \mathrm{mg} / \mathrm{L})$ when compared with the blank control group in the $4^{\text {th }}$ month. 
TCHO also increased steadily from the $1^{\text {st }}$ to $4^{\text {th }}$ month in the treatment groups when compared with the blank control and also with the $1^{\text {st }}$ month treatment mice, which is indicative of both low HDL- cholesterol plasma concentration and a less than functional HDL-cholesterol system, crucial for the effective reverse transport of cholesterol away from peripheral tissues as reported by Ouimet and colleagues in their paper cited above ${ }^{[22]}$. Plasma TG also followed a similar trend but was especially statistically significant in the treatment groups receiving $\mathrm{CdCl}_{2}(100 \mathrm{mg} / \mathrm{L}$ and $200 \mathrm{mg} / \mathrm{L}$ ). This increase is not only indicative of an increase in TG-rich lipoproteins [TRLs, which include chylomicrons, very low-density lipoproteins (VLDLs)and their remnants formed during the metabolism of lipoproteins], it also highlights findings from the investigations of Jia Peng and colleagues who indicated an integral role for hypertriglyceridemia and TG- rich lipoproteins in the etiology atherosclerosis ${ }^{[14]}$. These researchers opined that once in circulation, chylomicrons and VLDL can be hydrolyzed by lipoprotein lipase (LPL) along the luminal surface of capillaries, generating the production of free fatty acids and chylomicron remnants, and in succession progressively smaller VLDLs and intermediate density lipoproteins (IDLs), respectively all of which significantly contributes to the lipid content of the foam cells or plagues that eventually results asan end-product of atherosclerosis ${ }^{[34]}$. Pen-ultimately, fasting plasma insulin levels were observed to decrease in the $2^{\text {nd }}$ and $4{ }^{\text {th }}$ months of exposure in across all treatment groups when compared with the blank control as well as with the $1^{\text {st }}$ month treatment mice and were all found to be statistically significant $(P<0.05)$.

Evidently, results from this study suggests that sub-chronic exposure to Cd triggers an aberrant regulation of lipids, glucose and insulin in $\mathrm{ApoE}^{(--)}$mice which together may play a mechanistic role in the development of atherosclerotic plaques and ipso facto, atherosclerosis, in the aorta of ApoE ${ }^{(-/)}$mice. The latter is given credence by the development of atherosclerotic plaques seen in the aortal roots/lumen of the exposed mice when the histological examination 
was done in the $4^{\text {th }}$ month.

\section{Strengths and Limitations of Study}

A key strength of the present study is its huge translational potential. Since experimental results were supportive of a major role for sub-chronic $\mathrm{Cd}$ exposure in drinking water of experimental animals, public health practitioners could influence policy and the lifestyle of target populations in endemic areas to not only guard against personal exposure to this toxic heavy metal (Cd), but to also significantly mitigate industrial exposure from the activities of surrounding industries. Next, is in the use of $\mathrm{ApoE}^{(-/)}$mice which has been overtime demonstrated as being an excellent experimental model for the study of atherosclerosis. Finally, the present study was so finely organized allowing different groups to work on different aspects of sub-chronic Cd exposure, particularly organ-specific effects.

The first obvious weakness of the present study is the lack of comparison of the rate of development of atherosclerosis in both $\mathrm{ApoE}^{(-/)}$and wild-type mice simultaneously subjected to sub-chronic $\mathrm{CdCl}_{2}$ exposure in their drinking water. This would not only have increased the both the sample size and validity of research outcome, but would have also allowed for a more fluid extrapolation to human populations - since the typical person has not had the gene for the ApoE knocked-out.Another limitation of our study was the lack of a baseline data before the exposure period began which may have limited and adversely impacted on the outcome of our investigations. Further investigations in this area, should give this a priority. Next was the lack of an intervention or ameliorating agent once it has been established that sub-chronic Cd exposure interfered with both lipid and glucose metabolism and ipso facto cause atherosclerosis. A final limitation/weakness of this study is the inadvertent exclusion of sdLDL, oxLDL and oxLDLantibodies as one of the parameters assayed for in plasma of mice exposed to cadmium. This

would have increased the reliability of this investigation as Pozynak et. al ${ }^{[35]}$ reported that these biomarkers play a more direct role in the molecular etiology of atherosclerosis. 


\section{CONCLUSION}

Results from this study demonstrate that sub-chronic Cd exposure in the drinking water of ApoE ${ }^{(--)}$mice interfered with TCHO, TG, LDL, HDL, glucose and insulin levels, all of which may be associated with the development of advanced atherosclerotic plaques/lesions in the aortal roots of these mice as seen in the histological examination. Taken together, results from this investigation affirmatively answers our central research question as to whether Cd exposure alone could directly cause a disruption in lipid and glucose metabolism in $\mathrm{ApoE}^{(--)}$mice and also supports the overall research hypothesis that $\mathrm{ApoE}^{(--)}$mice will show a disruption in glucose and lipid metabolism and then progressively develop atherosclerosis when exposed to sub-chronic Cd treatment, especially at 100 and $200 \mathrm{mg} / \mathrm{L}$ (drinking water). 


\section{Ethical approval and consent to participate}

The present study is part of a large-scale project executed by the Food Safety and Health Research Center, Guangdong Key Laboratory of Tropical Disease Research, School of Public Health, Southern Medical University (SMU) and was granted ethical approval in accordance with the rules and guidelines of the Guangzhou CDC. Consent to participate in the present study was jointly granted me by the school of international education, SMU and my supervisor, Professor Xing-fen YANG.

\section{Consent for publication}

Not applicable

\section{Availability of data and materials}

All data generated or analyzed during this study are included in this published article [and its supplementary information files].

\section{Competing interests}

The authors declare that they have no competing interests

\section{Funding}

This study was funded by the National Natural Science Foundation of China (No.82073599).

\section{Authors' contributions}

ESO entered all experiment data into SPSS and Graphpad-prism software and also analyzed and interpreted all data, including writing the first draft of this manuscript. ESO also conducted key aspects of the benchtop experiments from which data was generated. YW performed some aspects of the experiments and also made significant contributions in scrutiny of the manuscript after the first draft was completed. Additionally, YW also placed orders for the procurement of all 
commercial kits used in this investigation. $\mathrm{HH}$ analyzed some of the data and also assisted in performing some aspect of the experiments. JS proof-read the entire manuscript after the first draft, ensuring that language of writing and data presentation were consistent with best practices. WZ and GY provided technical supports during strategy sessions and also help in the administration of feeds to mice. Additionally, they also provided professional observance of the animals and also made meaningful contributions during discussion sessions about the progress of the research. As corresponding author, XY did a full and exhaustive review of the present manuscript in full compliance with the requirements for corresponding authors as contained in the 'Editorial Policies' of this Journal.

\section{Acknowledgement}

Not applicable

\section{Authors' information:}

\section{${ }^{* a} X Y(P r o f e s s o r):$}

Director of Food Safety and Health Research Centre,

\section{Current Dean,}

School of Public Health,

Southern Medical University,

Guangzhou, PRC

Email: yangalice79@smu.edu.cn

Mobile: +86-20-6164-8301 


\section{$J S(P h D):$}

Post-doctoral fellow,

Food Safety and Health Research Centre,

Guangdong Provincial Key Laboratory of Tropical Disease Research,

School of Public Health,

Southern Medical University

Guangzhou, PRC

Email: jia_song1991@126.com

Mobile: +86-20-6164-8416

ESO:

MPH Student/PhD Candidate,

Food Safety and Health Research Centre,

Guangdong Provincial Key Laboratory of Tropical Disease Research,

School of Public Health,

Southern Medical University

Guangzhou, PRC

Email: samuelokpara16@gmail,com

Mobile: +86-13048056820

Alternate mobile: +2348067302495 
YW:

PhD student,

Food Safety and Health Research Centre,

Guangdong Provincial Key Laboratory of Tropical Disease Research,

School of Public Health,

Southern Medical University

Guangzhou, PRC

Email : 1451069184@qq.com

Mobile : +86-20-6164-8416

WZ :

Senior Research Fellow,

Guangzhou Center for Disease Control and Prevention,

Guangdong, China

Email: gzcdc_zhuw@gz.gov.cn

Mobile: +86-020-3605-5857

\section{GY:}

Senior Research Fellow,

Guangzhou Center for Disease Control and Prevention,

Guangdong, China

Email: ygy1225@126.com 
Mobile: +86-020-3654-5123

HH:

M.D. student,

Food Safety and Health Research Centre,

Guangdong Provincial Key Laboratory of Tropical Disease Research,

School of Public Health,

Southern Medical University

Guangzhou, PRC

Email: 1124743329@qq.com

Mobile: +86-20-6164-8416 


\section{REFRENCES}

[1] Carlos.G. et. al. Cadmium and atherosclerosis: Heavy metal or singing the blues? Atherosclerosis. 2016; 249: P230-P232

[2] Fransson M.N. et. al. Physiologically-based toxicokinetics model for cadmium using Markovchain Monte Carlo analysis of concentrations in blood, urine and kidney cortex from living kidney donors. Toxicol. Sci. 2014; 141: 356-376

[3] Jung D. Park et. al. Intestinal absorption of cadmium is associated with divalent metal transporter 1 in rats. Toxicol. Sci. 2002; 2: 288-294

[4] M. Berglund et al. Intestinal absorption of dietary cadmium in women depend on body iron stores and fibre intake. Environmental Health Perspec. 1994; 102 (12): 1058-66. doi: 10.1289/ehp.941021058

[5] Kishor B. Raja et al. Iron and Cadmium uptake by duodenum of hypotransferrinaemic mice. Biometals. 2006; 19(5):547-53. doi: 10.1007/s10534- 005-5919-4.

[6] Otsuka F, Sakakura K, Yahagi K, Joner M, Virmani R. 2014. Has our understanding of calcification in human coronary atherosclerosis progressed?Arterioscler Thromb Vasc Biol. 34:724-736.

[7] Virmani R, Joner M, Sakakura K. 2014. Recent highlights of ATVB: calcification. Arterioscler Thromb Vasc Biol. 34:1329-1332.

[8] Rader DJ, Daugherty A. 2008. Translating molecular discoveries into new therapies for atherosclerosis. Nature. 451:904-913. 
[9] Herder M, Arntzen KA, Johnsen SH, Eggen AE, Mathiesen EB. 2013. Long- term use of lipid-lowering drugs slows progression of carotid atherosclerosis: the Tromso study 1994 to 2008. Arterioscler Thromb Vasc Biol. 2013; 33:858-862.

[10] Puri R, Nissen SE, Shao M, Ballantyne CM, Barter PJ, Chapman MJ, Erbel R, Libby P, Raichlen JS, Uno K, Kataoka Y, Nicholls SJ. Antiatherosclerotic effects of long-term maximally intensive statin therapy after acute coronary syndrome: insights from Study of Coronary Atheroma by Intravascular Ultrasound: Effect of Rosuvastatin Versus Atorvastatin. Arterioscler Thromb Vasc Biol. 2014; 34:2465- 2472.

[11] Norberg G.F. et. al. Handbook on the Toxicology of Metals. Fourth ed. Elsevier, 2014

[12] L. Huang et. al., Cadmium uptake from the soil and transport by leafy vegetables. A metaanalysis. Environmental Pollution. 2020; 264: 1146-60.

[13] P. Zhu et al. Assessment of dietary cadmium exposure: A cross-sectional study of rural areas of South China. 2016; 62: 284-290

[14] Jia Peng et al. Hypertriglyceridimia and Atherosclerosis. Lipids in Health and Disease. 2017;16:233 Pp 2-12

[15] Avani E. et al. Apolipoprotein E knock-out and Knock-in mice: Atherosclerosis, metabolic syndrome and beyond. Journal of Lipid research. April 2009 supplement. PP S178-S182

[16] Toshio Hayashi et al. High glucose downregulates the number of caveolae in monocytes through oxidative stress from NADPH oxidase: Implications for atherosclerosis. Biochemica at Biophysica Acta 2007; 1772: 364-372.

[17] World Health Organization, Global Atlas on Cardiovascular Disease Prevention and Control, World Health Organization, Geneva, Switzerland, 2011.

[18] Virmani R, Joner M, Sakakura K. Recent highlights of ATVB: calcification. Arterioscler Thromb Vasc Biol. 2014;34:1329-1332. 
[19] Kumar A, Kumar S, Vikram A, Hoffman TA, Naqvi A, Lewarchik CM, Kim YR,Irani K. Histone and DNA methylation-mediated epigenetic downregulation of endothelial Kruppel-like factor 2 by low-density lipoprotein cholesterol. Arterioscler Thromb Vasc Biol. 2013; 33:1936-1942.

[20] Higashi Y, Maruhashi T, Noma K, Kihara Y. Oxidative stress and endothelial dysfunction: clinical evidence and therapeutic implications. Trends Cardiovasc Med. $2014 ; 24: 165-9$.

[21] Dickhout JG, Basseri S, Austin RC. Macrophage function and its impact on atherosclerotic lesion composition, progression, and stability: the good, the bad, and the ugly. Arterioscler Thromb Vasc Biol. 2008; 28:1413-5.

[22] Ouimet et al. HDL and reverse cholesterol transport: Basic mechanisms and their roles in vascular health and diseases. Circ Res. 2019 May 10; 124(10): 1505-1518.

[23] T. Hayashi, D. Sumi, P.A. Juliet, Gene transfer of endothelial NO synthase, but not eNOS plus inducible NOS, regressed atherosclerosis in rabbits, Cardiovasc. Res. 2004; 61: 339-351

[24] Boon RA, Dimmeler S. MicroRNA-126 in atherosclerosis. Arterioscler Thromb Vasc Biol. 2014; 34:e15-16

[25] Horie T, Baba O, Kuwabara Y, et al. MicroRNA-33 deficiency reduces the progression of atherosclerotic plaque in ApoE-/- mice. J Am Heart Assoc. 2012; 1: e003376.

[26] Schober A, Nazari-Jahantigh M, Weber C. MicroRNA-mediated mechanisms of the cellular stress response in atherosclerosis. Nature reviews Cardiology. 2015; 12:361-374.

[27] Kattor A. et al. Role of oxLDL and LOX-1 in Atherogenesis. Current Medicinal Chemistry. 201926 (9). 1693-1700 
[28] Hartley Adams et al., Oxidized LDL and anti-oxidized LDL antibodies in atherosclerosisnovel insights and future directions in diagnosis and therapy. Trends in Cardiovascular medicine. S1050-1738(18)30083-5

[29] Rafa S. Almeer et. al.l. Ryal Jelly mitigates cadmium-induced neuronal damage in mouse cortex. Molecular Biology Reports. 2019;46:119-131

[30] Toth PP, Barter PJ, Rosenson RS, Boden WE, Chapman MJ, Cuchel M, D'Agostino RB Sr, Davidson MH, Davidson WS, Heinecke JW, Karas RH, Kontush A, Krauss RM, Miller M, Rader DJ. High-density lipoproteins: a consensus statement from the National Lipid Association. J Clin Lipidol. 2013; 7:484-525.

[31] Degoma EM, Rader DJ. Novel HDL-directed pharmacotherapeutic strategies. Nat Rev Cardiol. 2011; 8:266-277.

[32] Klaus G. Parhofer. Increasing HDL cholesterol and prevention of atherosclerosis: A crucial perspective. Atherosclerosis Supplements. 2015; 18: 109-111

[33] Rader DJ, Daugherty A. Translating molecular discoveries into new therapies for atherosclerosis. Nature. 2008; 451:904-913.

[34] Johnson, L. A., J. M. Arbones-Mainar, R. G. Fox, A. A. Pendse, M. K. Altenburg, H. S. Kim, and N. Maeda. Apolipoprotein E4 exaggerates diabetic dyslipidemia and atherosclerosis in mice lacking the LDL receptor. Diabetes. 2011; 60: 2285-2294.

[35] Poznyak A. et al. The Daibetes Mellitus Connection-The role of lipid and glucose metabolism and chronic inflammation. Int. J. Mol. Sci. 2020; 21:1835

[36] Zhang X. et al. Effects of combined exposure to cadmium and high-fat diet on bone quality in male mice. Biological Trace Elements Research. 2019; 1-11 
[37] Qin Zhao et al. Acute oral toxicity test and assessment of combined toxicity of cadmium and aflatoxin $\mathrm{B}_{1}$ in Kunming mice. Food and Chemical Toxicology. 2019; $131: 110577$ 